\title{
Intraruminal infusion technique for the estimation of ruminal VFA production
}

\author{
P Huhtanen, S Jaakkola \\ Agricultural Research Centre, Institute of Animal Production, 31600 Jokioinen, Finland
}

The data from two $4 \times 4$ Latin square studies were used to estimate ruminal VFA production without radioactive isotopes. In Experiment $A$, a mixture of acetate (AC) and propionate ( $\mathrm{Pr})$ (3:1 on molar basis) was replaced isoenergetically with $0,200,400$ and $600 \mathrm{~g} / \mathrm{d}$ of butyrate $(\mathrm{Bu})$, and in Experiment $\mathrm{B}, \operatorname{Pr}$ was gradually replaced with $\mathrm{Bu}$ as follows $(\mathrm{g} / \mathrm{d})$ : $\operatorname{Pr} 900+\mathrm{Bu} 0, \operatorname{Pr} 600+\mathrm{Bu} 250, \operatorname{Pr} 300+\mathrm{Bu}$ 500 and $\operatorname{Pr} 0+\mathrm{Bu} 750$. The cows were fed a basal diet of grass silage and concentrate (app $0.6: 0.4$ on DM basis) twice daily. The mean dry matter (DM) intakes were 13.3 (Exp A) and $16.4 \mathrm{~kg} / \mathrm{d}(\operatorname{Exp} B)$. Rumen fluid samples were taken at $1.5 \mathrm{~h}$ intervals for $10.5 \mathrm{~h}$.

A regression approach of the technique used by Bath et al (1962, Proc Nutr Soc, 21, ix) was used to estimate ruminal VFA production of individual VFA. Production of $\mathrm{Bu}$ (or $\mathrm{Pr}$ ) was calculated by dividing the intercept by the slope of the regression : $y(\mathrm{mmol} / \mathrm{l}$ or $\mathrm{mmol} / \mathrm{mol})=a$ $+b x$, in which $x$ is the amount of $B u$ (or Pr) infused $(\mathrm{g} / \mathrm{d})$. Production of Ac (or other VFA) was calculated as $[((\mathrm{mmol} / \mathrm{mol} \mathrm{Ac}) /(\mathrm{mmol} / \mathrm{mol}$ $\mathrm{Bu})$ ) $\times \mathrm{Bu}$ production $(\mathrm{mmol} / \mathrm{d})]$ - amount of $\mathrm{AC}$ infused $(\mathrm{mmol} / \mathrm{d})$. These estimations are based on assumptions that there is an equilibrium between ruminal concentration and rate of absorption, and that the infusions did not alter the fermentation of the basal diet. Fairly high mean ruminal $\mathrm{pH}$ (6.34 and 6.35) and the fact that all cows received infusions may validitate these assumptions.

\begin{tabular}{lc}
\cline { 2 - 2 } & $\begin{array}{c}\text { Experiment A } \\
\text { From Bu }\end{array}$ \\
Acetate $(\mathrm{mol} / \mathrm{d})$ & 37.48 \\
Propionate $(\mathrm{mol} / \mathrm{d})$ & 10.05 \\
Butyrate $(\mathrm{mol} / \mathrm{d})$ & 9.23 \\
Other $\mathrm{VFA}(\mathrm{mol} / \mathrm{d})$ & 2.63 \\
Total $(\mathrm{mol} / \mathrm{d})$ & 59.39 \\
\hline
\end{tabular}

There was a close linear relationship between the amount of acid infused and molar proportion or concentration (not shown) in the rumen as the following regression equations show:
Exp A: Butyrate $y=124.2$ (s.e. 0.94) +0.163 (s.e. 0.0025 ) $x, r=0.9998$

Exp B : Butyrate $y=131.5$ (s.e. 4.91) +0.112 (s.e. 0.0105) $x, r=0.9913$

Propionate $y=162.3$ (s.e. 2.98) +0.113 (s.e. 0.0077 ) $\times, r=0.9977$

The highest rate of propionate infusion showed a quadratic trend (probably because of increased rate of absorption), and that point was not used to calculate the regression. The estimates of production of individual VFA are given in Table. The values calculated from $\mathrm{Bu}$ and $\mathrm{Pr}$ in $\operatorname{Exp} \mathrm{B}$ were similar, which suggests that there were no differences in the rate of absorption of these two acids. The energy value of VFA absorbed from the rumen was equivalent to 52 and $70 \%$ of the estimated $\mathrm{ME}$ which appear to be reasonable estimates. In terms of mol VFA per $\mathrm{kg}$ digestible DM the values are within the range reported by Sutton (1985, J Dairy Sci, 68, 3376-3393).

The results suggest that this method can give reasonable estimates of ruminal VFA production. It is recommended to use at least three rates of VFA infusion which makes the method laborious to be only used for estimation of VFA production.

\begin{tabular}{cc}
\multicolumn{2}{c}{ Experiment B } \\
\cline { 1 - 2 } From Bu & From $\overline{\mathrm{Pr}}$ \\
63.93 & 62.31 \\
17.08 & 16.60 \\
14.90 & 14.31 \\
3.86 & 3.82 \\
99.77 & 97.04
\end{tabular}

